\title{
Melatonina y jet lag iun suplemento alimenticio o un principio activo de interés militar?
}

Excmo. Sr. G. D. Médico Director de Sanidad Militar:

La desadaptación horaria (jet lag) afecta con frecuencia a los que viajan en avión y cruzan varias zonas horarias, como es el caso del personal militar en misiones internacionales.

Los síntomas del jet lag son principalmente fatiga diurna y trastornos del sueño, pero incluyen también pérdida de la eficiencia mental, debilidad e irritabilidad ${ }^{1}$.

La melatonina es una hormona liberada por la glándula pineal durante el periodo de oscuridad. Parece jugar un papel clave en la regulación de los ritmos circadianos, habiéndose utilizado desde el punto de vista terapéutico para la adecuación de los ritmos circadianos alterados.

Merece mención en el ámbito militar, un ensayo clínico realizado en soldados americanos en el que la melatonina ayudó a la adaptación circadiana y mantuvo las duraciones del sueño de siete a ocho horas en la zona de destino, mientras que con el placebo el sueño fue de cinco a siete horas. Además, en la pruebas cognitivas realizadas inmediatamente después de despertar, el grupo que recibía melatonina tuvo cerca de la mitad de errores del grupo que recibía placebo ${ }^{2}$.

En relación al jet lag, la biblioteca Cochrane ha realizado un metaanálisis de 10 ensayos clínicos (EECC) aleatorios con el fin de evaluar la eficacia de melatonina. La población a estudiar fueron pasajeros de líneas aéreas, personal de las líneas aéreas o personal militar a los que se administró melatonina oral versus placebo u otra medicación, valorando desadaptación horaria (a través de una escala visual analógica con puntuación de $0=$ nula desadaptación a $100=$ desadaptación completa) o componentes relacionados (bienestar, cansancio en horario diurno, comienzo y calidad del sueño, funcionamiento psicológico, duración del retorno a la normalidad) o indicadores de los ritmos circadianos. Los resultados muestran una diferencia de medias en la escala visual analógica entre el grupo que se le administró melatonina versus al grupo que se le administró placebo de -19,52 con un IC $95 \%$ de $-28,13$ a $-10,92$ en vuelos hacia el este y una diferencia de medias de $-17,27$ con un IC 95\% de -27,28 a -7,26 en vuelos hacia el oeste. Por otro lado, en 2 EECC se estudia como variable la proporción de personas con puntuación de desadaptación horaria $>60$, obteniendo una diferencia de riesgo de $-0,50$ con un IC $95 \%$ de -0.74 a -0.25 , a favor del grupo que recibía melatonina; por tanto, sólo sería preciso tratar a dos personas con melatonina en lugar de con placebo para evitar un desadaptación horaria $>60$.Respecto a la dosificación y seguridad de la melatonina, se muestra que las dosis diarias de melatonina entre $0,5-5$ mg son igual de efectivas, no habiendo mejoría con dosis superiores; que presentaciones de melatonina de vida media corta son más efectiva que las presentaciones de melatonina de liberación prolongada y que su uso ocasional a corto plazo por adultos se considera seguro ${ }^{3}$.
La melatonina está comiercializada como suplemento alimentario desde hace más de 20 años en EEUU, así como en otros países, como Canadá, México, Argentina, Venezuela, Rusia, Polonia, Hungría o Italia ${ }^{4}$.

En España es considerada como principio activo con actividad farmacológica, no aceptándose su comercialización como complemento alimenticio según la Agencia Española de Medicamentos y Productos Sanitarios (AEMPS). La primera autorización por parte de la Agencia Europea del Medicamento (EMA) de este principio activo (en comprimidos de liberación prolongada de $2 \mathrm{mg}$ ) se ha realizado en junio de 2007, sin embargo aún no está comercializado el medicamento en nuestro país y su indicación se ha restringido, según ficha técnica, al tratamiento a corto plazo del insomnio primario en pacientes mayores de 55 años ${ }^{4-6}$.

Herxheime A y Petrie KJ, en la revisión realizada sobre melatonina y jet lag, señalan que el uso de ésta el día del viaje y hasta 4 días después de la llegada puede aumentar marcadamente la efectividad y eficiencia del despliegue militar ${ }^{3}$.

Los autores nos preguntamos si teniendo en cuenta la eficacia, seguridad, utilidad militar y la no comercialización de este suplemento alimenticio/principio activo en España, debiera plantearse la incorporación en el Petitorio de Farmacia de la melatonina y su fabricación por parte de los Laboratorios Farmacéuticos Militares.

\section{BIBLIOGRAFÍA}

1. Sack R. Jet Lag. N Engl J Med 2010; 362: 440-7

2. Comperatore CA, Lieberman HR, Kirby AW, Adams B, Crowley JS. Melatonin efficacy in aviation missions requiring rapid deployment and night operations. Aviat Space Environ Med, 1996; 67: 250-4

3. Herxheime A, Petrie KJ. Melatonina para la prevención y tratamiento de la desadaptación horaria (“jet lag») (Revisión Cochrane traducida). En: La Biblioteca Cochrane Plus, 2008 Número 2. Oxford: Update Software Ltd. Disponible en: http://www.update-software.com. (Traducida de The Cochrane Library, 2008 Issue 2. Chichester, UK: John Wiley \& Sons, Ltd.).

4. CLAVIS. Disponible en: http:// www. melatonina.es/articulos/224-2010-02-28. html. Consultado: 08/06/2011

5. AEMPS. Disponible en: https://sinaem4.agemed.es/consaem/fichasTecnicas. do?metodo=buscar. Consultado: 08/06/2011

6. EMA. Disponible en:

http://www.ema.europa.eu/docs/es_ES/document_library/EPAR_-_Product_Information/human/000695/WC500026811.pdf Consultado: 08/06/2011

Cte. Médico García-Luque A. Tcol. Médico Puerro Vicente M. Hospital Central de la Defensa Gómez Ulla. Servicio de Farmacología Clínica. 